Research Article

\title{
Numerical Analysis of Temperature Influence on Transverse Cracks in Concrete Box-Girder Bridges
}

\author{
Hanzheng Xu iD and Xiaofeng Yan \\ School of Highway, Chang'an University, Xi'an, Shaanxi 710064, China \\ Correspondence should be addressed to Hanzheng Xu; 897692148@qq.com
}

Received 7 July 2020; Accepted 23 July 2020; Published 20 August 2020

Academic Editor: Yumin Cheng

Copyright (c) 2020 Hanzheng Xu and Xiaofeng Yan. This is an open access article distributed under the Creative Commons Attribution License, which permits unrestricted use, distribution, and reproduction in any medium, provided the original work is properly cited.

\begin{abstract}
Concrete box-girder bridges are widely used in China. During several routine inspections of two-year-old highway bridges of this type in the China Central Plains region, we found that transverse cracks are widespread on the bottom flanges of those box girders, mainly distributed in the area of $1 / 4 L$ to $3 / 4 L$ of the span. Selected cracks were then monitored continuously for one year. Our results showed that there had been no change in the widths of the cracks, but their lengths had increased and new cracks had formed. Taking into consideration factors like hydration reaction, relative humidity difference, shrinkage and creep, sunlight thermal differential effect, sudden temperature change, vehicle load, and their combined efforts, we have developed spatial structural models and conducted stress analyses on the reinforced concrete and prestressed concrete box-girder bridges, respectively. Our numerical analysis results indicated that the hydration reaction is the main reason for the initial bottom flange crack and the temperature difference between the inside and the outside of the box girders caused the crack developments at the later stage.
\end{abstract}

\section{Introduction}

Concrete bridge structures are influenced by a variety of natural conditions where environmental thermal actions, such as solar radiation, ambient temperature, and wind, play major roles. Consequently, the temperature distribution varies and is changing all the time. The change is influenced by many factors, such as geographical location, solar radiation condition and intensity, and orientation of the structure and seasons. For concrete bridges, the heat exchange exists invariably on the structure surface through radiation, convection, and conduction. Since the heat exchange process is quite complex, a very complicated thermal load is formed [1].

At the beginning of the 1950s, the importance of thermal stress to concrete structures was recognized by research from the former Federal Republic of Germany when an onsite survey analysis of thermal stress of a concrete pier was carried out. Similar research was completed by the Major Bridge Engineering Group Corporation of the Chinese
Ministry of Railways in the late 1950s and by others around the world. In the early days of temperature-induced stress research, only the temperature variations of the year were considered. With the progress of the experiment and theoretical study, people started to realize that thermal distribution in the concrete structure was a nonlinear question. By the 1950s, based on the conclusion of Stephenson from Great Britain, engineers started to consider the temperature difference between sun and shade.

With its long-span capability, good bearing performance, and convenient installation, prestressed concrete (PC) continuous box-girder bridges have been widely used in bridge design since the 1960s in China. But during the construction or the operation phases, many serious cracks were found on bridges in China and in other countries as well. Fritz Leonhardt mentioned in his study that the range of temperature differences between the upper limb and lower edge could be $27^{\circ} \mathrm{C}$ to $33^{\circ} \mathrm{C}$ when measured on boxgirder and rib girder bridges. Most cracks on prestressed concrete box-girder bridges were caused by thermal stress. 
Mirambell and Aguado briefly presented an analytical model to predict temperature and stress distributions [2]. Some remarks related to the vertical and transverse temperature differences were introduced. Barr et al. measured the temperature, strains, and cambers on five girders of a prestressed concrete bridge and a matching test girder to study stress and camber changes caused by elevated curing temperatures and by variations in service temperatures [3]. Subramaniam et al. developed an understanding of temperature changes induced by hydration heat release in the first few hours after casting in the thermal movements and stresses of the concrete deck and girders [4]. Experimental and analytical studies were conducted on a prestressed concrete girder by Lee to determine the transverse and vertical thermal gradients of prestressed concrete girders [5]. In China, Liu proposed a practical calculation method of thermal stress and received good results upon comparison with the actual measurement [6]. Ye et al. conducted a one-year observation of the temperature effect on a continuous prestressed concrete box-girder bridge during construction in order to determine the most unfavorable positive and negative values of temperature difference in a concrete box girder [7]. Fang and Wang discussed the temperature field and its variation laws of the box-girder bridge based on a four-day continuous observation of thermal differential effect on a long-span continuous prestressed concrete box-girder bridge [8].

In the past, researchers concentrated on the temperature difference in sunlight when the study of thermal stress in concrete box-girder bridges was conducted. Although it is more difficult to analyze sunlight temperature distribution because of its complexity and rapid change, there is a lot of achievements in this field compared with the study of sudden temperature change. Relatively, the amount of research on thermal effect caused by sudden temperature change is not sufficient. As is commonly known, concrete is a nonperforming thermal conductivity material, so when the ambient temperature changes sharply, the outside temperature changes at nearly the same rate as the environment, but the internal temperature does not change as much. As a result, a large temperature gradient develops in box girders, and, meanwhile, deformation appears. If the deformation is restrained by material fiber and boundary conditions, it will produce thermal stress. But based on current research, a conclusion cannot be reached as to what kind of damage it will cause and whether or not it will lead to cracks on reinforced concrete (RC) and PC bridges.

Geometric nonlinearity is one of the most important topics in civil engineering, mechanical engineering, hydraulic engineering, aviation, and materials engineering. In the geometric nonlinear state, the strain-displacement relationship is nonlinear, and the large deformation makes the corresponding problems difficult to solve [9]. At present, with the development of computer technology, the main numerical methods of stress analysis of box-girder bridge are finite element method and meshless method. Among them, the finite element method is currently the most widely used numerical analysis method. It divides the continuum into discrete structures composed of finite grids, which we call elements. Then, the approximate function of each element is used to solve the unknown variables in the whole problem domain. This method is easy to master, convenient, practical, and adaptable. The theoretical research on finite element method has been very mature, and scientists have also developed a variety of finite element software, such as ANSYS, ABAQUS, and MSC [10]. For the formation and propagation of cracks, we can combine fracture mechanics with the finite element method, which is consistent with the actual stress state even with coarse element meshes [11].

As the finite element method has the more cumbersome step of meshing and the inaccuracy of solving specific problems, the meshless method came into being. In the meshless method, the computational domain is replaced by some discrete nodes, and there is no need to use elements or grids to interpolate field variables, and the relationship between nodes can be changed. This method can partially or completely eliminate the grid and get rid of the limitation of the elements. Therefore, the meshless method has caught more interest in the large deformation problem, crack growth problem, metal forming problem, and other special problems, without reconstructing the mesh [12]. But this method needs to solve the interpolation coefficient of each point in the problem domain. Meshless method is based on the nodes to establish approximation function, and it does not need the remesh of the solution domain when studying large deformation problems. It can increase the density of nodes to obtain the solutions with higher-computational accuracy [13]. There are many ways to construct the trial function, and one of the most commonly used methods is the moving least-squares (MLS) approximation [14]. Because the method is based on the MLS approximation, it may form ill-conditioned equations, which results in an incorrect solution. By orthogonalizing the basis functions, Cheng and Chen presented interpolating moving least-squares (IMLS) approximation to overcome the shortcoming of MLS approximation. Research shows that, in numerical examples, the influences of the penalty factor, scale parameter of influence domain, and weight functions on the computational accuracy are analyzed, and the numerical solutions show that the improved elementfree Galerkin (IEFG) method for elastoplastic large deformation problems has higher-computational efficiency and accuracy [15]. However, the amount of calculation is still very large. Moreover, this method started late, and the theoretical research is not as mature as the finite element method. After comprehensive consideration, this paper adopts finite element numerical analysis method.

This paper will focus on actual stress states in the reinforced concrete and prestressed concrete bridges while drastic temperature variation occurs. We have presented in the paper a suitable temperature distribution according to continuous observation on a box-girder bridge in central plains region of China. To analyze the temperature effect, we have built finite element models (FEM) and studied the temperature's effect on the cause of cracks. Moreover, we have suggested feasible solutions to avoid the issues on the bridge related to the change of temperature. For example, over the last two decades and especially in recent times, smart materials have attracted immense interest and have been studied intensively worldwide by both intradisciplinary and multidisciplinary research groups [16]. 


\section{Causes of Crack}

With the rapid economic development in China, great progress in bridge construction has taken place. New bridges are designed and built on a continuous basis. Among them, a large proportion is box-girder bridges, mainly in concrete. Based on long-term routine bridge inspections, many cracks have been found on box-girder bridges, even if they were designed as prestressed concrete bridges with no crack allowance. Some of them are quite serious. Some of the example cracks are shown in Figures 1 and 2.

Due to numerous cracks at the bottom of girders, some bridges were strengthened, as shown in Figure 3, which took huge manpower and material resources. But many bridges with a similar problem remain under observation without reinforcement.

In Yun Xing's paper "Study on the Capability against Cracking of the Pre-Stressed Concrete Box-Girder Bridges from the Design Aspect," he found that "live load should not be the main factor influencing the cracking of a long-span prestressed concrete continuous beam bridge" through analysis and comparison of three different span bridges. Because the thickness and overall rigidity of the concrete structure are large and compared with the dead load, the proportion of live load is small. Beyond vehicular load on the bridge, wind load and temperature load could also be factors. In the central plains region of China, wind power is not as strong as it is in other regions of China so its effect can be excluded. Therefore, the thermal load was speculated to be the main cause of this type of crack.

\section{Temperature Effect on Concrete Box- Girder Bridge}

Thermal stress can be divided into two parts. The first part is called thermal self-restraint stress. The strain that the fiber undergoes in the internal concrete structure is not the same due to different temperatures between external and internal structures. Because of the mutual constraint between fibers, diverse strain leads to thermal self-restraint stress. The second part is called secondary thermal stress. Each component of the internal system deforms out of phase under different temperatures. These deformations are restricted by external constraints. Then, the secondary thermal stress comes into place. Thermal stress is practically nonlinear and sometimes the stress and strain do not obey Hooke's law.

There are four main external factors that affect the temperature of the concrete structure, namely, (1) the hydration heat of cement, (2) the change of annual temperature, (3) sunlight, and (4) sudden changes in temperature. R. Springenschmid believes that $2 / 3$ of the stress of concrete comes from temperature changes, and $1 / 3$ comes from shrinkage and swelling. The heat of hydration of cement is the main source of early temperature stress of concrete, and temperature stress is a very important factor in the early cracking of concrete. Analyzing the temperature changed by cement hydration heat is complicated, but this heat can be regulated by controlling the construction temperature. Annual temperature change is somewhat an average temperature

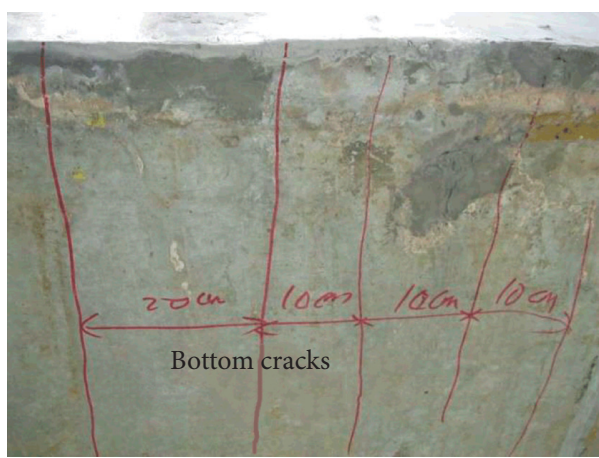

Figure 1: Transverse cracks on the bottom of the slab.

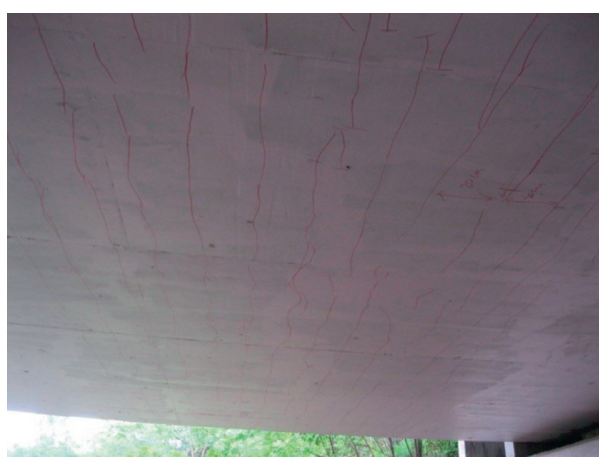

Figure 2: Serious cracks on the bottom of the slab.

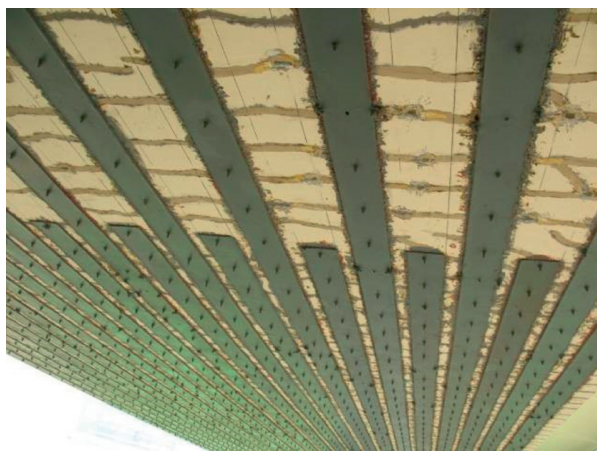

Figure 3: Bottom slabs strengthened.

change for box girders caused by physioclimate. This change is slow, and its primary result is longitudinal displacement for a bridge. The displacement can be adjusted by the expansion joint or support displacement or set up by the flexible pier and so on to deal with the problem [17]. Under the blazing sun for a long period of time, the temperatures of the panel, main girder, and pier are obviously higher than those of other parts. Due to their own constraints, partial principal tensile stress is high and may result in cracks. Wind, cold air, and lack of sunlight lead to sudden change in temperature across the structure surface. However, since the internal temperature change is relatively slow, temperature gradient develops. This is part of the reason that may raise the principal tensile stress, leading to the cracking phenomenon.

The first two thermal loads are simple to control. Because of the amount of well-established research on temperature 
difference due to sunlight, this paper will not go into detail on the subject. For box-girder bridges, a sudden change in temperature produces a complicated distributed load. It is instantaneous and uneven and has a major effect on local thermal stress. This is one of the main reasons that cause the box-girder cracking.

Sunlight causes sudden temperature change and annual temperature change. These changes will affect the different characteristics of the thermal load, as listed in Table 1.

In concrete structures, the thermal state of each point that is internal or on the surface of the structure at a certain moment is called thermal distribution. Due to the low coefficient of thermal conductivity of concrete, the obvious hysteresis occurs in the internal temperature changes in case of abrupt changes in surface temperature. As a result, there is a large difference in the formation of each layer of structure components or heat diffusion nonlinear temperature state.

Thermal load considered in this paper is mainly caused by a drastic temperature drop. When weather changes dramatically, ambient temperature changes can reach $10^{\circ} \mathrm{C}$ within 24 hours. At that moment, the external temperature variation of a box-girder bridge is relatively uniform, but the temperature changes through the thickness direction very different. Commonly, steel bar has a small effect on thermal distribution, and its influence can be ignored.

Thermal load acting on an engineering structure is generated by weather conditions. The thermal load of an engineering structure is a function that changes over time. Together with the thermal distribution, which is multidimensional in geometry, analyzing the load is complicated and demanding a rigorous analytical solution is impossible. The so-called "thermal load analysis of an engineering structure" is loosely defined as the use of different calculation methods to determine the distribution of a specific temperature in an engineering structure. For a certain internal or surface point of an engineering structure, the temperature $T_{i}$ at a certain moment can be expressed as

$$
T_{i}=f(x, y, z, t)
$$

where $T_{i}$ of the point is not only associated with the coordinates $x, y$, and $z$ but also has relationship with time $t$. Therefore, for homogeneous material, we can derive the following three-dimensional unsteady heat conduction equation according to the Fourier heat conduction theory:

$$
\lambda\left(\frac{\partial^{2} T}{\partial x^{2}}+\frac{\partial^{2} T}{\partial y^{2}}+\frac{\partial^{2} T}{\partial z^{2}}\right)=c \gamma \frac{\partial T}{\partial t}-q
$$

In equation (2), $\lambda$ refers to thermal conductivity, $c$ refers to specific heat capacity, $\gamma$ refers to volume-weight, and $q$ refers to the heat released within the unit volume.

The measured data shows that the heat conduction state of a concrete structure can be approximated by a one-dimensional heat conduction state. From a practical point of view, the approximation is allowed so that the complexity of the problem may be greatly simplified. Since the measured temperature distribution along the longitudinal direction of the bridge is always relatively even, the temperature difference can then be neglected through the longitudinal direction of the bridge. On a bridge deck, there is always a main heat conduction direction. For example, the heat conduction along the vertical direction is much greater than it is along the horizontal direction when influenced by solar radiation. Therefore, the heat conduction through the horizontal direction, which is quite small, can be omitted.

In the initial transient heat conduction, the known function of the temperature field coordinates is $T_{0}(x, y, z)$; that is, when $t=0$, the initial transient temperature distribution can be considered as constant; that is, $T=f(x, y, z, 0)=T_{0}=$ constant.

The actual value of the concrete surface temperature may be measured by the sensors, so the first boundary condition is selected. That is,

$$
T(t)=f(t)
$$

Since the temperature difference can be neglected along the longitudinal direction of the bridge, the heat conduction equation can be written as

$$
\alpha \frac{\partial^{2} T}{\partial x^{2}}=\frac{\partial T}{\partial t}
$$

in which $\alpha$ refers to the thermal conductivity of concrete, $\alpha=(\lambda / c \gamma)$.

Referred by Stephenson, Priestlay, and Liu, the following semitheoretical and semiempirical formula can be used for the one-dimensional temperature field:

$$
\bar{T}(y)=\bar{T}_{(\text {oy })} e^{-\bar{c}_{y} y}+c,
$$

where $\bar{c}_{y}$ is an exponential percentage, $\bar{T}_{\text {(oy) }}$ refers to negative temperature difference of box-girder siding, and $y$ refers to the distance of a calculated point away from the outside board.

\section{Field Measurement}

This test case is a prestressed concrete continuous box-girder bridge with uniform cross section in central China. It is an east-west bidirectional four-lane bridge, $116 \mathrm{~m}$ in length and $10 \mathrm{~m}$ in width. The span combination is $23+2 \times 35+23 \mathrm{~m}$ in four spans. The design load conforms to Chinese highway level one load. That is, for lane load, the uniform distributed load is $10.5 \mathrm{kN} / \mathrm{m}$. The concentrated load is selected in accordance with the following provisions: when bridge calculated span is less than or equal to $5 \mathrm{~m}, P_{\mathrm{K}}=180 \mathrm{kN}$; when the calculated span greater than or equal to $50 \mathrm{~m}$, $P_{\mathrm{K}}=360 \mathrm{kN}$; if bridge span is between the two, $P_{\mathrm{K}}$ is obtained by interpolating. The main beam material is C50 concrete. In order to study the impact of a sudden change in the temperature of a box girder, a long-term continuous observation was carried out in the autumn and the winter of 2011 in every half-hour interval. The test was to primarily measure the environment temperature and the temperature of the box-girder surface. Figure 4 is the overall layout of the testing section. $T 1$ to $T 4$ are locations of four testing sections. Cross-sectional temperature measuring points are shown in Figure 5. 
TABle 1: Contrast of different thermal loads.

\begin{tabular}{|c|c|c|c|c|c|}
\hline Type & $\begin{array}{l}\text { Influencing } \\
\text { factors }\end{array}$ & Temporality & Scope & $\begin{array}{c}\text { Distribution } \\
\text { characteristics }\end{array}$ & Effect \\
\hline $\begin{array}{l}\text { Sunlight temperature } \\
\text { changes }\end{array}$ & Solar radiation & Short-term rapid change & Partial & Uneven & High local stress \\
\hline $\begin{array}{l}\text { Sudden drop in } \\
\text { temperature changes }\end{array}$ & Severe cold air & Short-term changes & Total & Uniform & High stress \\
\hline $\begin{array}{l}\text { Annual temperature } \\
\text { change }\end{array}$ & $\begin{array}{c}\text { Slow temperature } \\
\text { changes }\end{array}$ & Long-term and slow & Total & More uniform & $\begin{array}{l}\text { Large overall } \\
\text { displacement }\end{array}$ \\
\hline
\end{tabular}

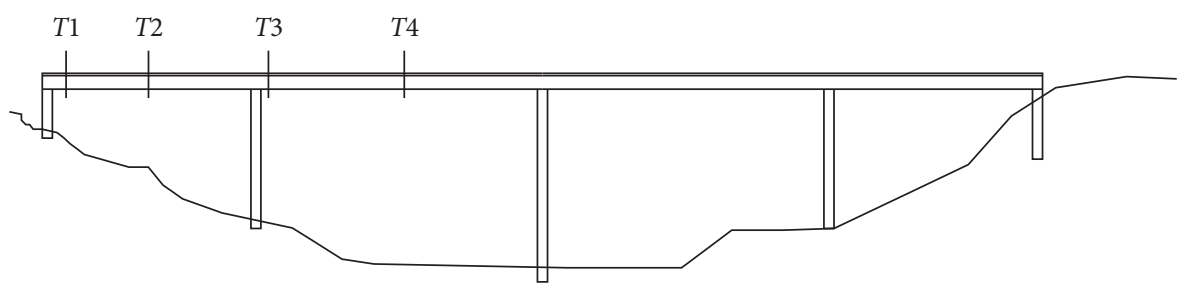

FIgURE 4: Measuring point layout.

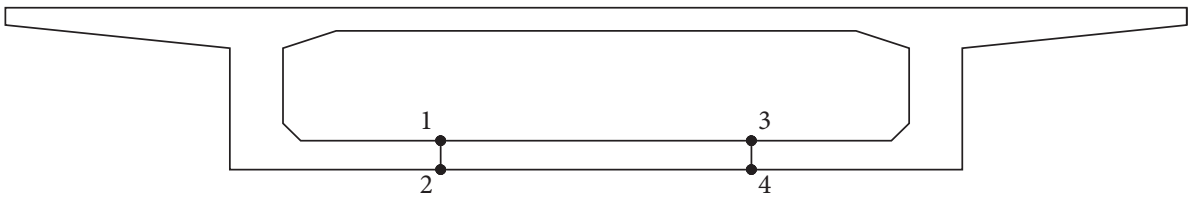

FIGURE 5: Measuring point layout on section.

4.1. Change of External Temperature. According to the meteorological data, the temperature records of drastic temperature changes for analysis were figured out. Figure 6 is the temperature test record with a cold wave. The figure shows that the highest temperature of the surrounding environment is $7.7^{\circ} \mathrm{C}$ and the lowest temperature is $-10.5^{\circ} \mathrm{C}$. Thus, the maximum temperature difference is $-18.2^{\circ} \mathrm{C}$. The highest surface temperature of the box-girder bridge is $7.4^{\circ} \mathrm{C}$, the lowest temperature is $-10.9^{\circ} \mathrm{C}$, and the maximum difference in temperature is then $-18.3^{\circ} \mathrm{C}$. The test results show that the box-girder surface temperature and ambient temperature are roughly the same.

4.2. Internal Temperature Change. Figure 7 is the box-girder internal temperature change. The test results show that the box-girder maximum internal temperature is $7.3^{\circ} \mathrm{C}$, the lowest temperature is $0.4^{\circ} \mathrm{C}$, and the maximum difference in temperature is $6.9^{\circ} \mathrm{C}$.

4.3. Difference between the External and Internal Temperatures. With the comparison of the temperature curve between the inside and the outside, both can be seen to follow roughly the same trend. But due to low concrete thermal conductivity, the internal temperature change of box girders is more gradual than the outside. Figure 8 shows the contrast curves of inside and outside temperatures. As can be seen from Figure 9, when the ambient temperature changes dramatically, a large temperature difference can be expected. As a result of this survey, a maximum difference was reached in the early morning at $-12.8^{\circ} \mathrm{C}$.

4.4. Results Analysis. According to the measured temperature data, the maximum box-girder temperature difference between the inside and the outside was $-12.8^{\circ} \mathrm{C}$. At that time, the outside temperature of the box girder was $-10.5^{\circ} \mathrm{C}$, and the inside was $2.3^{\circ} \mathrm{C}$. The bottom plate thickness was $0.25 \mathrm{~m}$. Following the semitheoretical semiempirical formula shown in equation (5), based on the measured temperature curve, the approximate distribution of temperature along the thickness direction can be obtained:

$$
\bar{T}_{(y 1)}=-12.8 e^{-38 y}+2.3 \text {. }
$$

\section{Numerical Analysis}

5.1. Assumption of Temperature Stress. In the stress calculation caused by thermal load, the temperature distribution along the girder longitudinal direction is assumed to be fairly uniform, and the small differences in the distribution due to small change of the cross section are ignored. Concrete is considered a homogeneous and isotropic material, and it is in line with the law of elastic deformation before cracking. The planar cross-section assumption is tenable. Thermal stress is firstly calculated under individual load of temperature difference and then superimposed. 


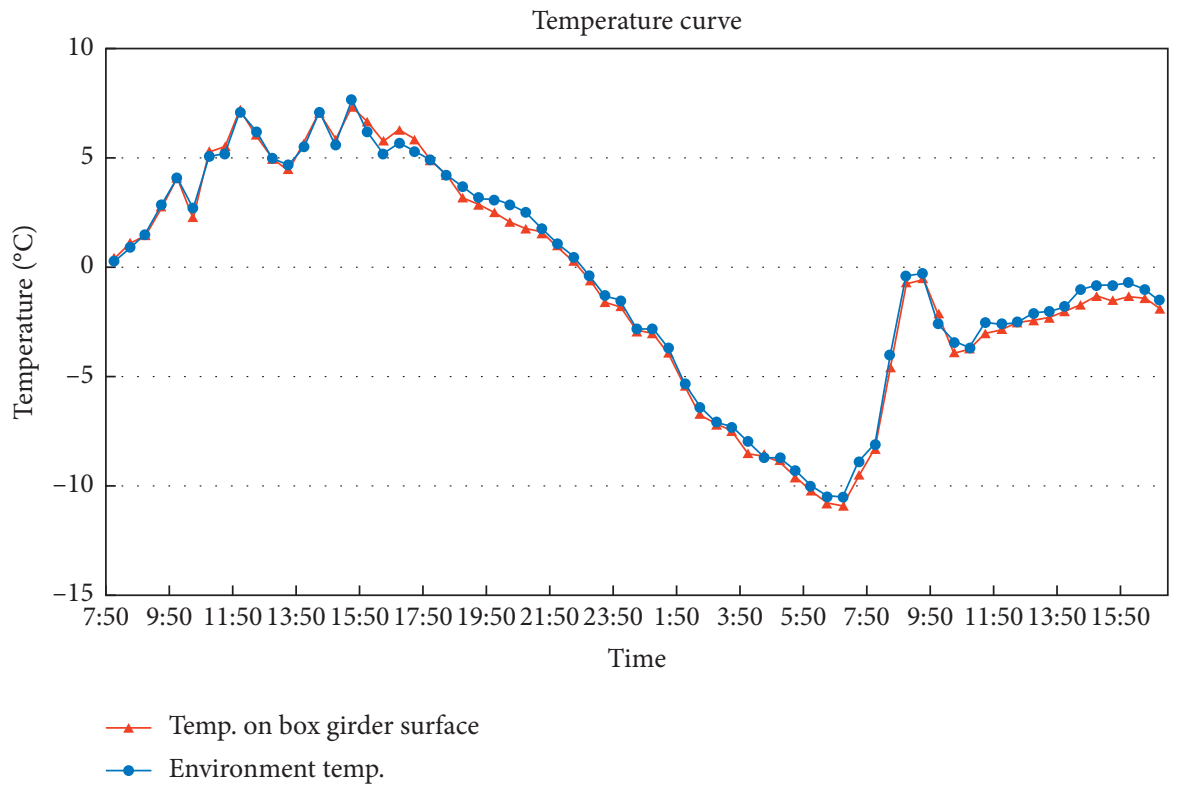

FIgURE 6: External temperature test curve of the box girders.

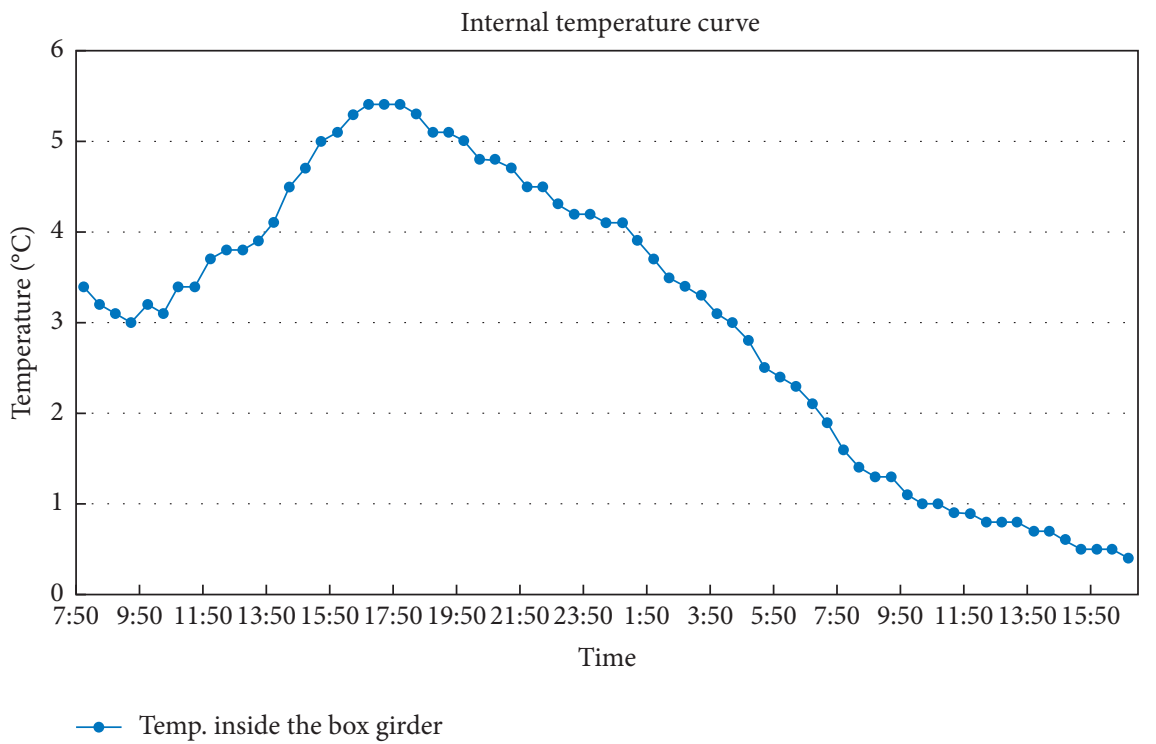

Figure 7: The box girders internal temperature test curve.

5.2. Finite Element Modeling (FEM). A box girder was modeled with a bridge-dedicated analysis software. A typical single-box single-cell girder cross section is selected for this bridge. An eight-node solid element was used to simulate and analyze with measured parameters. There were 50,715 nodes and 41,560 elements for the RC model and 50,747 nodes and 41,576 elements for the PC model. The cross section of the box girder is shown in Figure 10 and the finite element model is shown in Figure 11.

Materials of the model are shown as follows:

(i) Concrete: C50; modulus of elasticity: $34500 \mathrm{MPa}$; Poisson's ratio: 0.2 ; single shaft ultimate tensile strength: $2.6 \mathrm{MPa}$; single shaft ultimate compressive strength: $32.4 \mathrm{MPa}$; bulk density: $2460 \mathrm{~kg} / \mathrm{m}^{3}$. (ii) Prestressed reinforcing steel: $\mathrm{Rj}=1860 \mathrm{MPa}$; diameter: $15.24 \mathrm{~mm}$

Four working conditions are set:

(i) Condition 1: dead load + effect of temperature difference between the inside and the outside of the box.

(ii) Condition 2: dead load + effect of temperature difference between the inside and the outside of the box + live load.

(iii) Condition 3: dead load + effect of temperature difference between the inside and the outside of the box + prestress. 


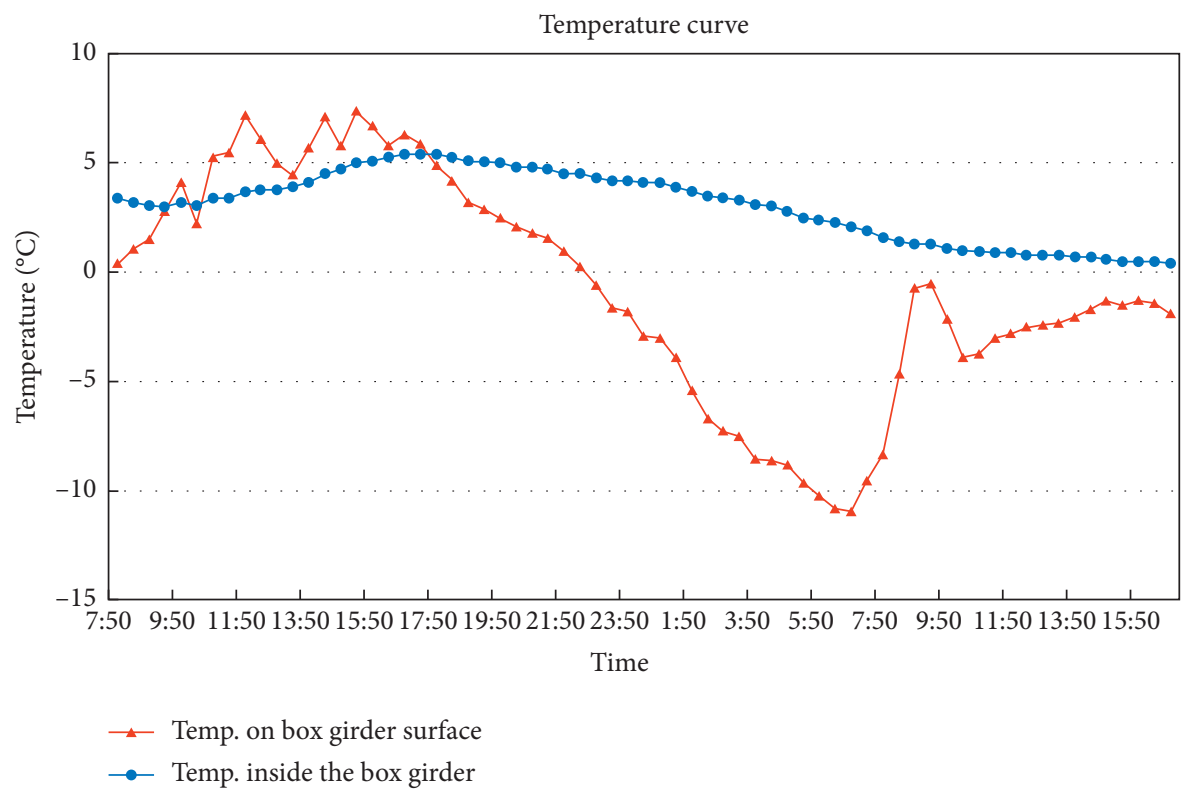

Figure 8: Inside and outside temperature contrast.

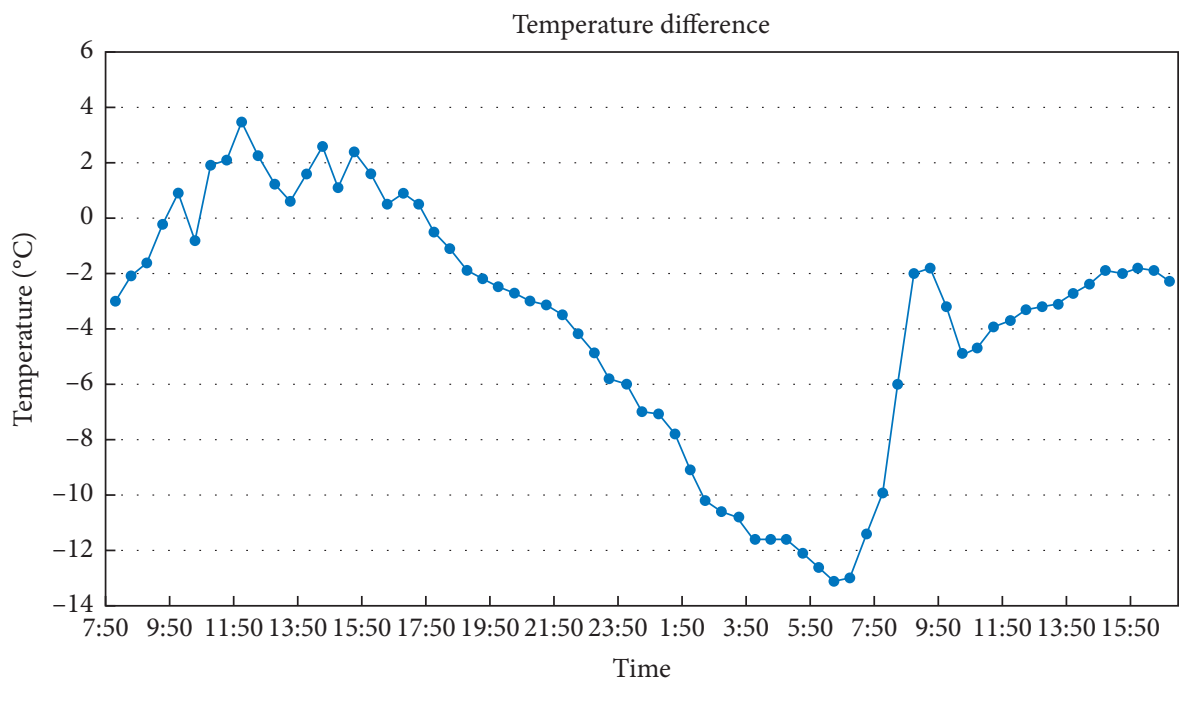

- Temp. difference between inside and outside

Figure 9: Changing curve of temperature difference.

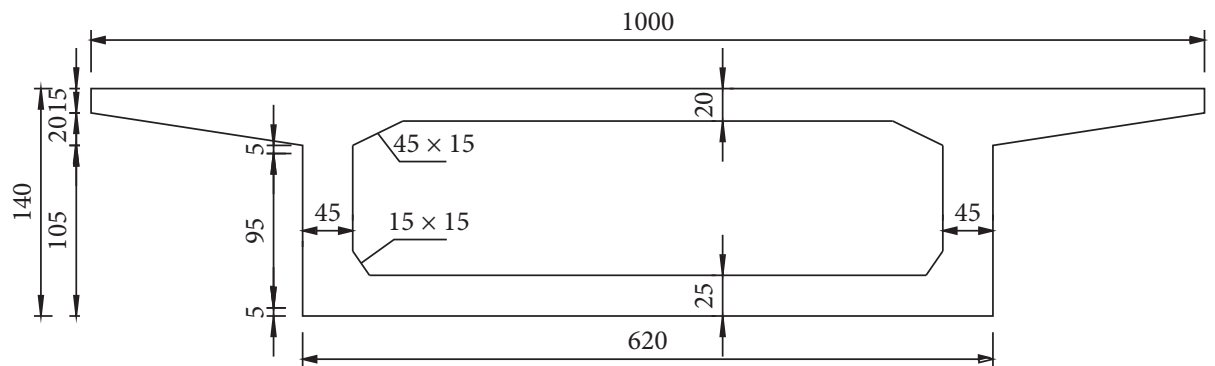

Figure 10: Box-girder cross section. 


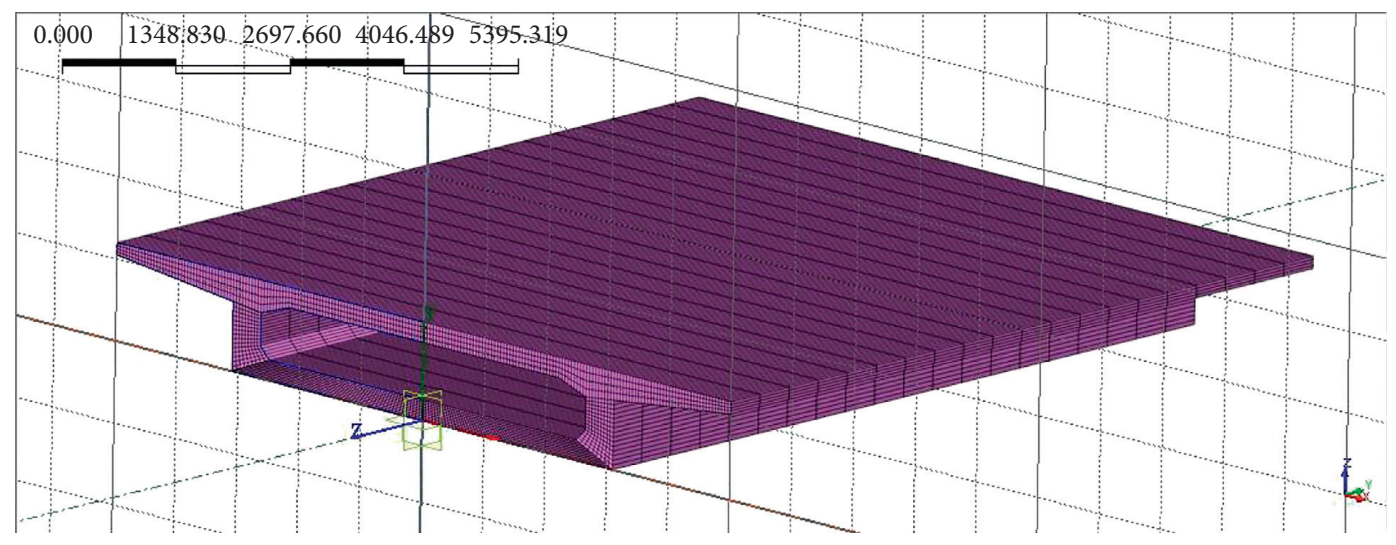

Figure 11: FEM model.

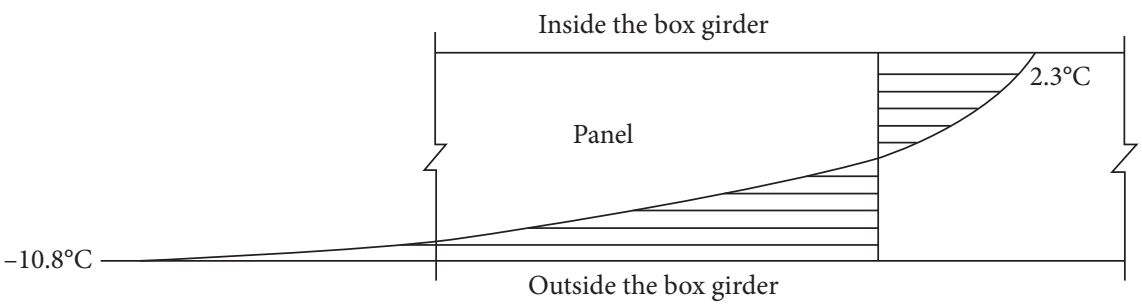

FIgURE 12: Temperature distribution along the beam thickness direction.
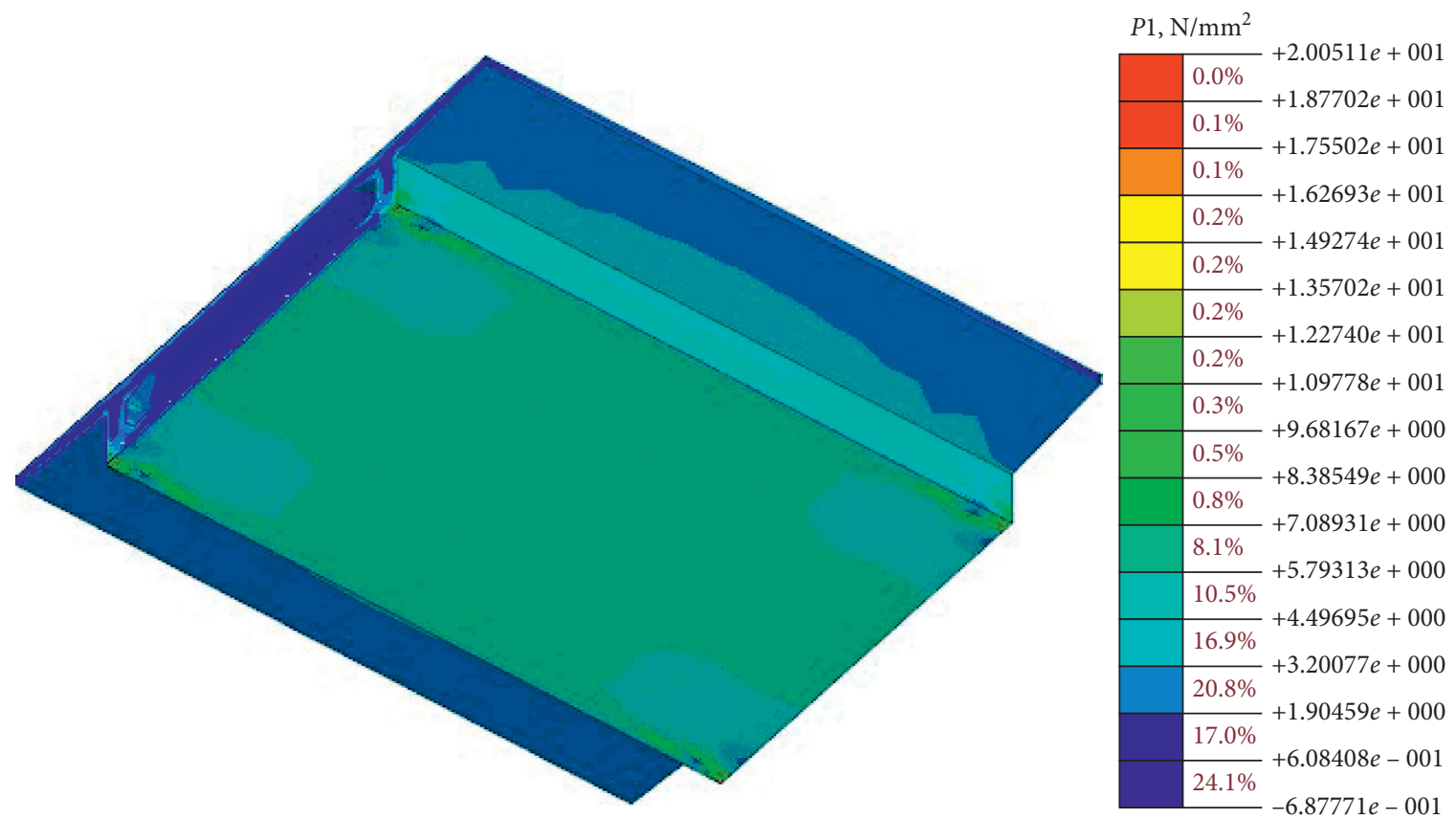

FIgURE 13: Condition 1: dead load + effect of temperature difference.

(iv) Condition 4: dead load + effect of temperature difference between the inside and the outside of the box + prestress + live load.

Temperature distribution is considered as $\bar{T}_{(y 1)}=$ $-12.8 e^{-38 y}+2.3$. The temperature distribution along the box beam thickness direction is shown in Figure 12.
5.3. Results of Various Working Conditions. Results of working Conditions 1 and 2 are shown in Figures 13 and 14, respectively.

For the reinforced concrete bridge, the results of the calculation by Condition 1 show that, with only the temperature effect, the maximum stress of the lower edge of the base plate has reached $5.9 \mathrm{MPa}$, while the C50 concrete 


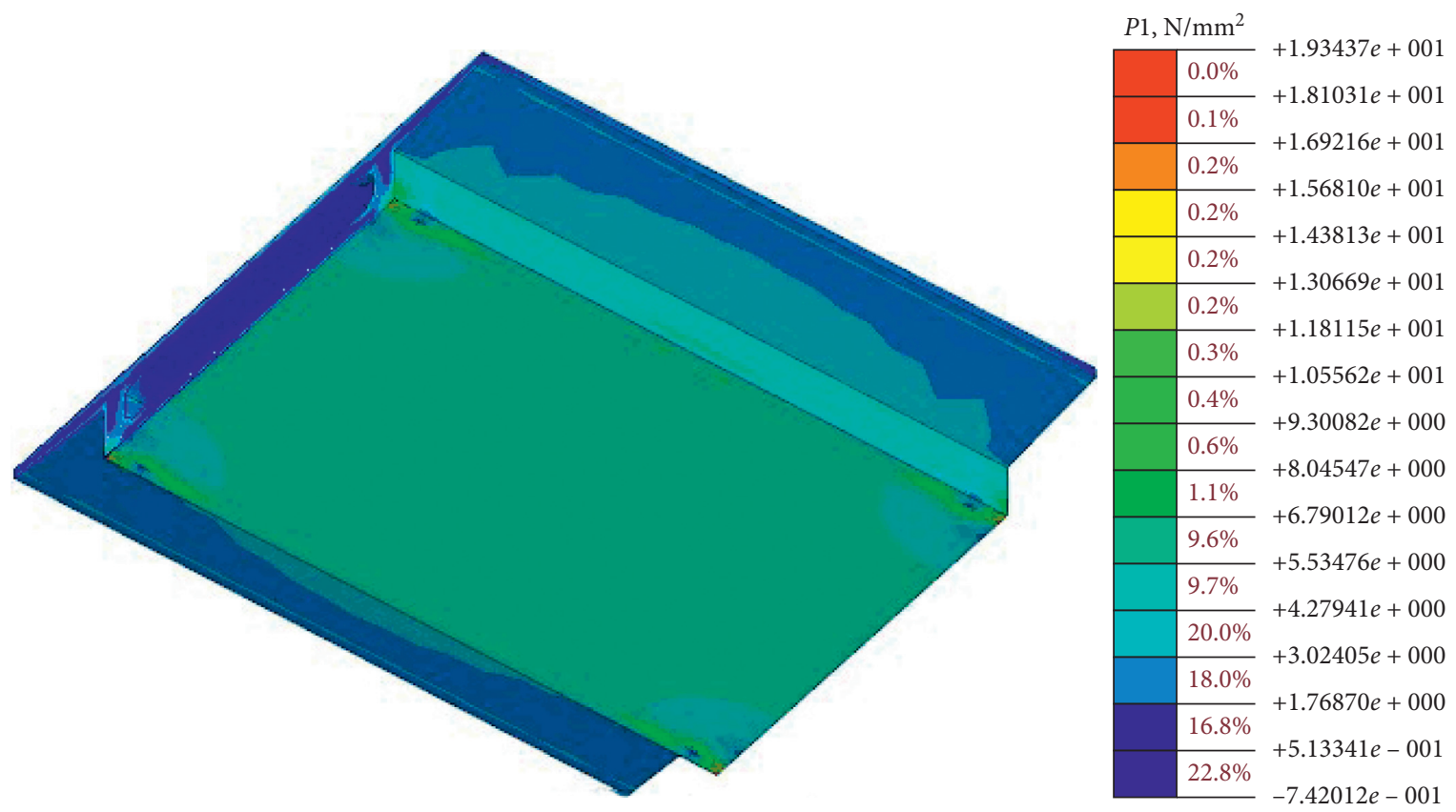

Figure 14: Condition 2: dead load + effect of temperature difference + live load.
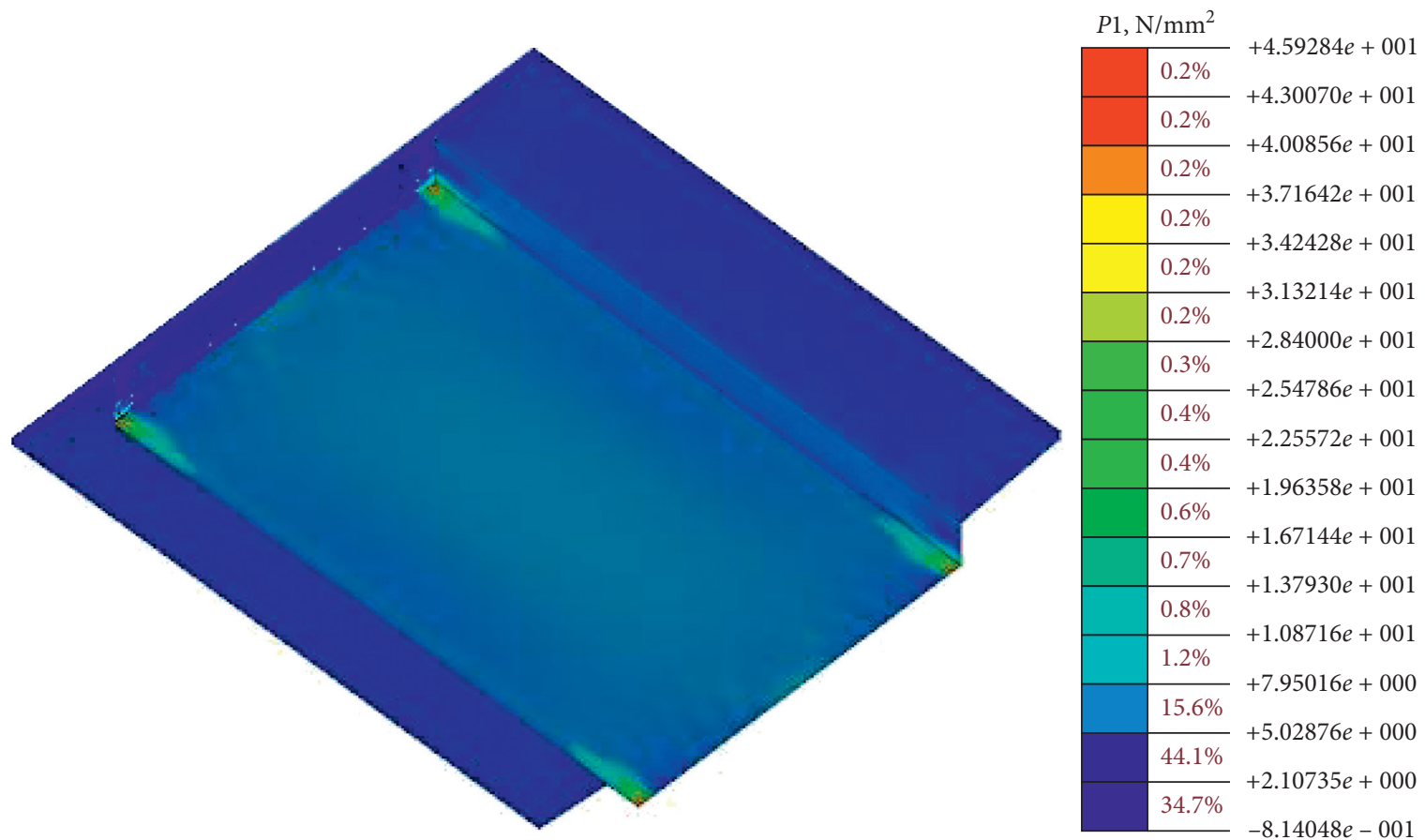

FIGURE 15: Condition 3: dead load + effect of temperature + prestressed.

tensile strength is only $2.6 \mathrm{MPa}$. Therefore, only under the influence of the dead load and the temperature difference between the inside and outside of the box girder, the edge of the box girder will crack. When the vehicle load (Condition 2 ) is added, the tensile stress of lower edge increases further. Therefore, in the actual operational process, if the cold wave occurs near the bridge site region, the bottom of the box girder would form a large crack under the combined action of dead load, vehicle load, and the temperature difference between the inside and the outside of the box.

Results of working Conditions 3 and 4 are shown in Figures 15 and 16, respectively.

For a prestressed concrete bridge, the results of the calculation by Condition 3 show that the stress of the bottom slab is between 1.9 and $2.3 \mathrm{MPa}$ when affected by dead load, temperature difference, and prestressed force. Compared with 


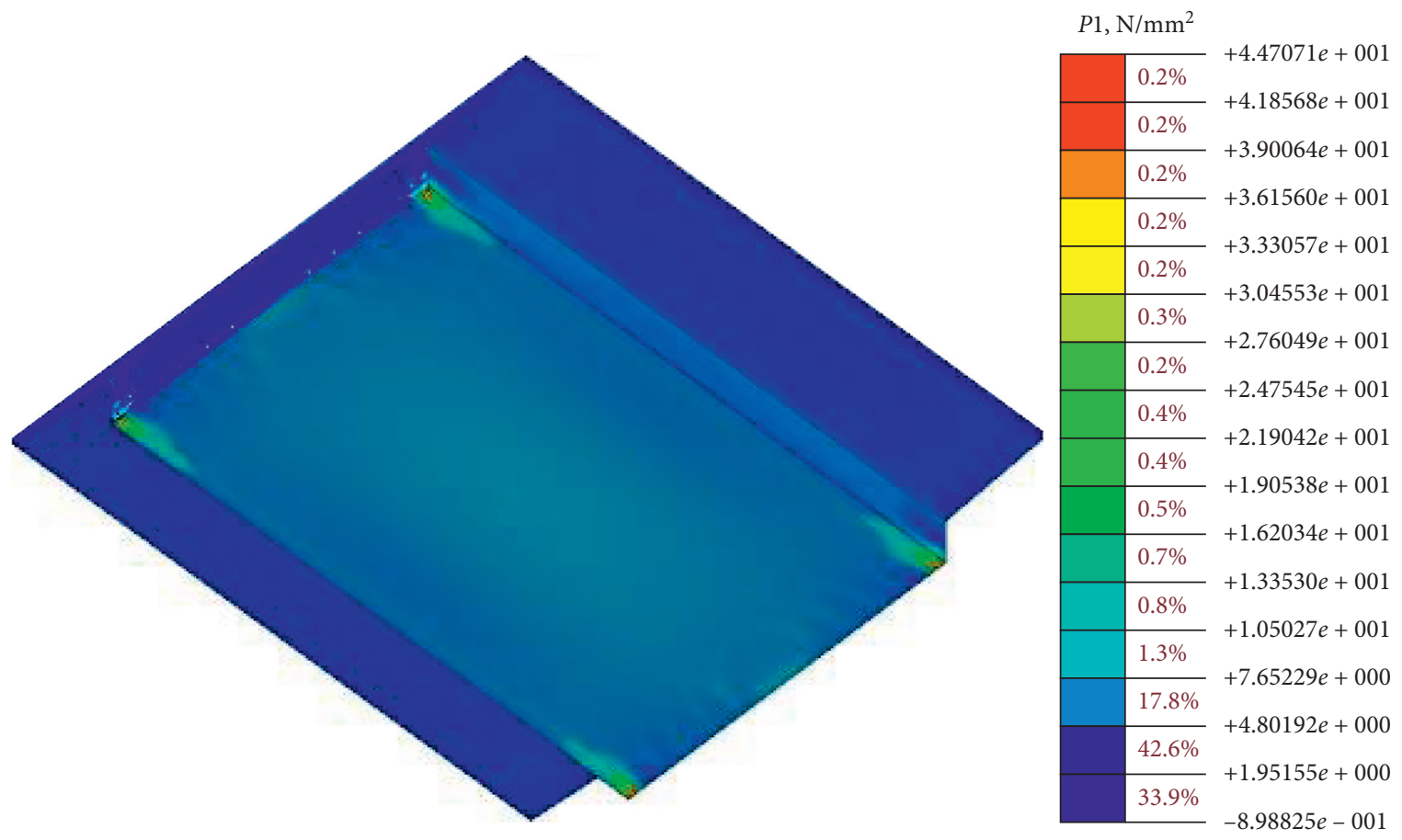

Figure 16: Condition 4: dead load + effect of temperature + prestressed + vehicle load.

the tensile strength of the concrete, $2.6 \mathrm{MPa}$, the difference between them is small. Due to the quality of on-site pouring, concrete strength is discrete. Hence, there would be some parts with insufficient strength. This may also cause cracking.

The results of Condition 4 show that, under the effect of dead weight, temperature, and vehicle load, the stress of the bottom slab is still up to $3.4 \mathrm{MPa}$, even for a prestressed concrete bridge. Average stress also reaches 2.7 MPa. A prestressed concrete box girder in the actual process operation will still crack, especially within an area with extreme weather.

In summary, compared with the reinforced concrete structure, despite the fact that prestressed concrete structures' force has greatly improved, the tensile stress on the bottom of the box girder generated by temperature difference and vehicle load is generally higher than the tensile strength of the concrete. Thus, it is likely to crack in practice. The thermoelectric effect along the bridge longitudinal direction is not in effect. As a result, if there is cracking, it would cover the whole bottom slab, which corresponds to the actual observations (as illustrated in Figures 1 and 2).

\section{Conclusion}

We have studied in this paper the influence of the temperature on the cause of cracking in concrete box-girder bridges, based on our inspections of highway bridges of this type in the China Central Plains region. The cause of cracking was first investigated, followed by the case study on the field measurement. To analysis the cracking issue, we have built finite element models for four different working conditions such as dead load and the effect of temperature difference between the inside and the outside of the box. Our results reveal that, due to the temperature difference between the inside and the outside of the box, the thermal self-restraint stress comes into place. Affected by temperature difference, the tensile stress of the bottom slab exceeds the tensile strength of the concrete. Moreover, building more ventilation holes to enhance the box-girder internal and external heat exchange is more effective to make inside and outside temperatures closer and to help reduce the probability of cracking caused by temperature differences. However, since this study focuses mainly on the thermal differential effect in the central plains of China. Due to differences in geographical environments, the environmental conditions of bridges in nearby locations are not all the same. Therefore, future reference values of thermal differential effects in different regions need to be collected in the future to extend the study.

\section{Data Availability}

The data used to support the findings of this study are available from the corresponding author upon request.

\section{Conflicts of Interest}

The authors declare that they have no conflicts of interest.

\section{References}

[1] H. Tian, G. Li, F. Li, and H. Kong, Spatial Effect Analysis of Internal and External Temperature Differences of Box Girder Bridge, Bridge Construction, London, UK, 2006.

[2] E. Mirambell and A. Aguado, Temperature and Stress Distribution in Concrete Box Girder Bridges, ASCE, Reston, VA, USA, 1990. 
[3] P. J. Barr, J. F. Stanton, and M. O. Eberhard, "Effects of temperature variations on precast, prestressed concrete bridge girders," Journal of Bridge Engineering, vol. 10, no. 2, p. 186, 2005.

[4] K. V. Subramaniam, J. Kunin, R. Curtis, and Donald Streeter, "Influence of early temperature rise on movements and stress development in concrete decks," Journal of Bridge Engineering, vol. 15, no. 1, pp. 108-116, 2010.

[5] J.-H. Lee, "Investigation of extreme environmental conditions and design thermal gradients during construction for prestressed concrete bridge girders," Journal of Bridge Engineering, vol. 17, no. 3, pp. 547-556, 2012.

[6] X. Liu, "Prestressed concrete box girder temperature stress calculation method," China Civil Engineering Journal, 1986.

[7] J. Ye, L. Xiao, and Yi Wang, Study of Characteristic Value of Thermal Difference of Concrete Box Girder Based on Statistical Analysis, Highway traffic technology, 2009.

[8] Z. Fang and J. Wang, "Sun light thermal difference effect on long-span PC continuous box girder bridge," China Journal of Highway and Transport, vol. 20, no. 1, pp. 62-67, 2007.

[9] F. Liu and Y. Cheng, "The improved element-free Galerkin method based on the nonsingular weight functions for elastic large deformation problems," International Journal of Computational Materials Science and Engineering, vol. 7, 2018.

[10] Y. Xing, Study on the Capability against Cracking of the Prestressed Concrete Box Girder Bridges from the Design Aspect, Tongji University, Shanghai, China, 2008.

[11] A. Hillerborg, M. Modéer, and P.-E. Petersson, "Analysis of crack formation and crack growth in concrete by means of fracture mechanics and finite elements," Cement and Concrete Research, vol. 6, no. 6, pp. 773-781, 1976.

[12] Y. Deng, X. He, and Y. Dai, "The improved interpolating complex variable element free Galerkin method for two-dimensional potential problems," International Journal of Applied Mechanics, vol. 11, no. 10, Article ID 1950104.

[13] F. Liu and Y. Cheng, "The improved element-free Galerkin method based on the nonsingular weight functions for inhomogeneous swelling of polymer gels," International Journal of Applied Mechanics, vol. 10, no. 4, 2018.

[14] Y. Deng and X. He, "An improved interpolating complex variable meshless method for bending problem of," Kirchhoff Plates, vol. 9, no. 6, p. 23, 2017.

[15] F. Liu, Q. Wu, and Y. Cheng, "A meshless method based on the nonsingular weight functions for elastoplastic large deformation problems," International Journal of Applied Mechanics, vol. 11, no. 1, 2019.

[16] R. Huang, S. J. Zheng, Z. S. Liu, and T. Y. Ng, "Recent advances of the constitutive models of smart materialshydrogels and shape memory polymers," International Journal of Applied Mechanics, vol. 12, no. 2, Article ID 2050014, 2020.

[17] S. N. Shoukry, G. W. William, and M. Y. Riad, Response of an Integral Abutment Bridge to Temperature Variations, ASCE), Reston, VA, USA, 2008. 